\title{
Compensation Design Using RLS Algorithm for THD Reduction in a Solar PV Hybrid System
}

\author{
Satyam Kumar Prasun \\ M.Tech. Scholar \\ Dept. of Electrical \& Electronics \\ Engineering \\ Corporate Institute of Science \& \\ Technology, Bhopal, India \\ prasun.satyam@gmail.com
}

\author{
Sanjeev Jarariya \\ Assistant Professor \\ Dept. of Electrical \& Electronics \\ Engineering \\ Corporate Institute of Science \& \\ Technology, Bhopal, India \\ SanjeevJarariya@gmail.com
}

\author{
Avinash kumar \\ M.Tech. Scholar \\ Dept. of Electrical \& Electronics \\ Engineering \\ Corporate Institute of Science \& \\ Technology, Bhopal, India \\ avinashthakur0009@gmail.com
}

\begin{abstract}
PV and wind hybrid are found to be the most lucrative solution for the diminishing traditional energy sources. Whereas these alternatives sources of the energy have many remarkable rewards like cost of energy and feasibility etc. The attributes of these sources of being cost effective and stable are possible due to their complementary nature as compared to independent energy systems. Therefore, these systems have admirable capability to meet energy crisis up to some extent. The proposed word has designed a hybrid energy system fit for driving residential loads using MATLAB/SIMULINK software. The work has proposed a compensator with RLS algorithm is place of traditional STATCOM device. The results has sown that the active power output available at the load terminal improved from $400 \mathrm{KW}$ to $700 \mathrm{KW}$. Also the work has analyzed THD level in voltage and current waveforms. The proposed RLS based compensator reduced the THD level in voltage to $0.81 \%$ and in current wave form to $1.26 \%$. The model has also been integrated with the grid in order to make the system more reliable and efficient while driving loads
\end{abstract}

Keywords: Hybrid solar-wind systems, STATCOM, compensator, RLS algorithm, total harmonic distortion

\section{INTRODUCTION}

The future energy demand is increasing rapidly while the conventional energy resources are depleted. As a result, the world is looking for alternative sources of energy. There are promising sources of hybrid distributed generation, such as; wind generator, solar PV, fuel cell, small hydro, biomass, geothermal, tides, wave generator. Wind generator and solar PV are the most commonly used. The integration of small modular generation and energy storage to low or medium voltage distribution systems forms a new type of power system, named the micro grid $(\mu \mathrm{G})$. The $\mu \mathrm{G}$ can operate in grid-connected mode or in islanded mode, where it appears to the main grid as a single load or source depending on whether load is higher than the generating source in the area. Moreover, DGs and loads may be located close to each other or distributed geographically. Therefore, it provides higher flexibility and reliability. Grid-connected $\mu \mathrm{G}$ is capable of supplying energy on its own, allowing it to operate in connection with an electrical power system, or to form an independent system for power supply. Small-scale systems represent one type of the key renewable energy applications.

\section{1) System- architecture \& modeling}

The proposed system is which is composed of PV arrays, DC/DC converter, with MPTT, AC/DC inverter, a Fixed Speed Wind turbine system with induction generator and three phase load. The DGs are connected in AC architecture. WT is directly connected to PCC, whereas $\mathrm{PV}$ arrays are connected to PCC via boost converter and voltage source inverter (VSI).

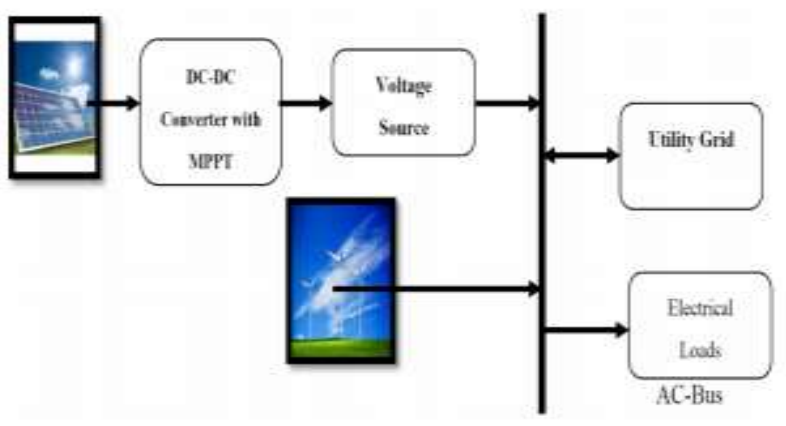


Figure 1 System architecture of small scale hybrid PVWT grid connected system

\section{LITERATURE REVIEW}

Ying Liu et al. [1] In this paper are the rapid developments of new energy generation, the influence of large-scale wind/solar hybrid system on power system transient voltage stability cannot be ignored. First, largescale wind/solar hybrid system model is established based on simulation software Power Factory/Dig SILENT in this paper. An advanced control strategy for hybrid model by adding a damping controller in the rotor side of DFIG is proposed. The analysis results show that the effect of wind/solar hybrid system mode on system voltage oscillation is the lowest compared with the wind turbines operating separately mode and PV panels operating separately mode. The stability and safety of the power grid based on the hybrid system are improved. Finally, the efficiency and accuracy of the proposed control scheme are validated by simulation software Power Factory/Dig SILENT.

Hamdy M. Sultan et al. [2] In this paper, the impact of integrating photovoltaic plants (PVPs) with high penetration levels into the national utility grid of Egypt is demonstrated. The results of frequency stability analysis proved that the national grid could be maintained stable even when the PVPs reached a penetration level up to $3000 \mathrm{MW}$ of the total generation in Egypt. Transmission network upgrading to accommodate up to $3000 \mathrm{MW}$ from the proposed PV power plants by 2025 is suggested. In addition, analysis of voltage stability manifests that the dynamic behavior of the voltage depends remarkably on the short circuit capacity of the grid at the point of integrating the PVPs.

A Arabali et al. [3] This paper proposes a stochastic framework for optimal sizing and reliability analysis of a hybrid power system including the renewable resources and energy storage system. Different percentages of load shifting and their potential impacts on the hybrid power system reliability/cost analysis are evaluated. Using a compromise-solution method, the best compromise between the reliability and cost is realized for the hybrid power system.

S. Wang et al. [4] This paper presented are the 4 operation modes and 15 working states of wind/PV hybrid power system were induced by the analysis of its energy flow and operation characteristics, and a coordination control scenario which contains maximum power tracking control, load tracking control, charge and discharge control for battery as well as operation with protection was put forward. Simulation results verify the correctness and feasibility of the coordination control scenario proposed in the paper for wind/PV hybrid system.

\section{OBJECTIVE}

First, large-scale wind/solar hybrid system model is established based on simulation software MATLAB in this work. The work need to further deal with the following main objectives:

- To design a simple but highly viable compensator for a gird connected solar wind hybrid system that is capable of feeding less distorted voltage to the load along with enhancement in power output.

- To present an optimal controlling of these compensators so as to minimize the voltage distortion by designing a rls algorithm for the same.

- To reduce the distortion level in the current waveform as well such that the system efficiency is enhanced and the power is being fed to the load and the grid with minimum distortion.

- To further enhance the proposed design such that it is practically feasible to be implemented in grid system having renewable energy resources as well as is capable of driving the residential loads.

\section{METHODOLOGY}

The large-scale wind/solar hybrid system is connected to grid via a booster station. The system consists of wind power system and photovoltaic system. In order to improve the transient voltage stability of the large-scale wind/solar hybrid system, reactive power compensation device STATCOM is connected to grid. The compensator is being proposed for further enhancement in the output parameters like THD in voltage, THD in current and active power output.

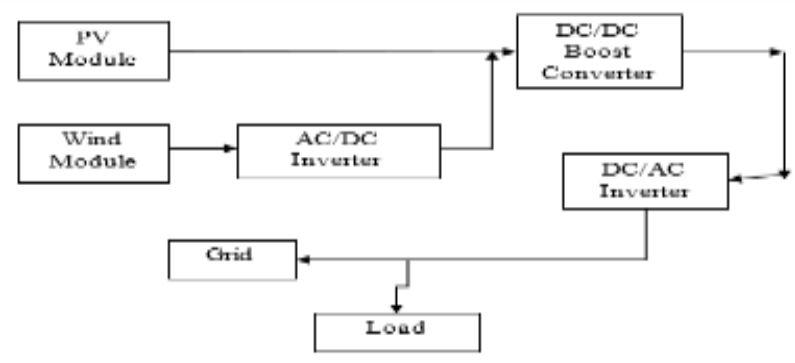

Figure 2: Hybrid energy system topology

\section{1) PV Module modelling:}

PV cells have single operating point where the values of the current (I) and voltage (V) of the cell result in a maximum power output. These values correspond to a particular resistance, which is equal to V/I. A simple equivalent circuit of PV cell. 


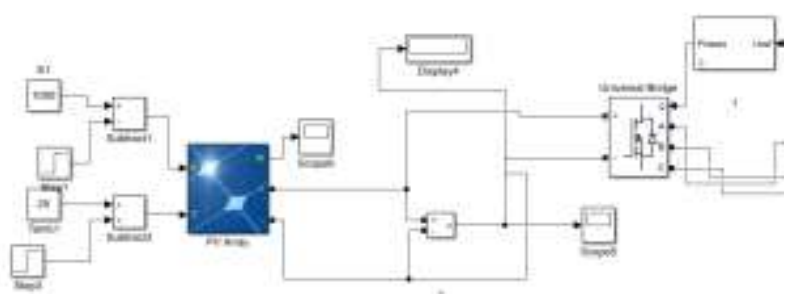

Figure 3 Modeled solar system

A cell series resistance ( Rs ) is connected in series with parallel combination of cell photocurrent ( $\mathrm{I}_{\mathrm{ph}}$ ), exponential diode ( D ), and shunt resistance $\left(R_{\text {sh }}\right)$, I pv and Vpv are the cells current and voltage respectively. It can be expressed as

$$
\begin{gathered}
I_{p v}=I_{p h}-I_{s}\left(e^{q\left(V_{p v}+I_{p v} * R_{s}\right) / n K T}-1\right)-\left(V_{p v}+I_{p v}\right. \\
\left.* R_{s}\right) / R_{s h}
\end{gathered}
$$

Where:

I ph - Solar-induced current

$I_{S}$ - Diode saturation current

$q$ - Electron charge $\left(1.6 \mathrm{e}^{-19} \mathrm{C}\right)$

$K$ - Boltzmann constant $\left(1.38 \mathrm{e}^{-23} \mathrm{~J} / \mathrm{K}\right)$

$n$ - Ideality factor (1 2)

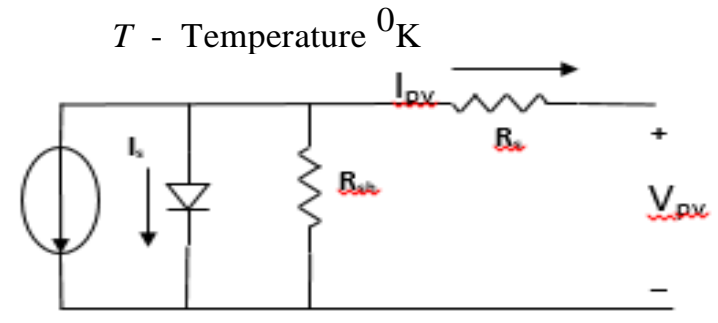

Figure 4 Equivalent circuit of solar pv cell

The solar induced current of the solar PV cell depends on the solar irradiation level and the working temperature can be expressed as:

$$
I_{p h}=I_{s c}-k_{i}\left(T_{c}-T_{r}\right) * \frac{I_{r}}{1000}
$$

Where:

$I_{S C}$ Short-circuit current of cell at STC

$K_{i}$ Cell short-circuit current/temperature coefficient $(\mathrm{A} / \mathrm{K})$

$I_{r}$ Irradiance in $\mathrm{w} / \mathrm{m}$

$T_{c}, T_{r}$ Cell working and reference temperature at STC

A PV cell has an exponential relationship between current and voltage and the maximum power point (MPP) occur at the knee of the curve.

www.ijoscience.com

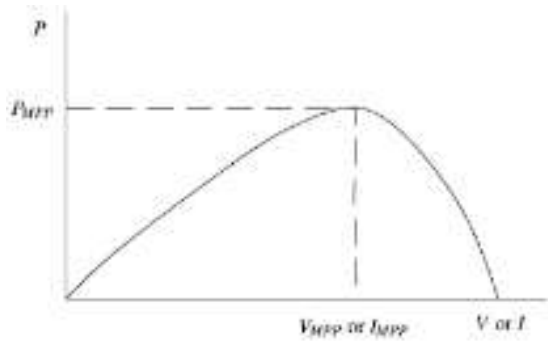

Figure 5 Characteristic $\mathrm{PV}$ array power curve The $\mathrm{P} \& \mathrm{O}$ algorithm will track the maximum power to supply the DCMGs system. The assumptions for model derivation are that the ideal current source can be presented as the PVs behavior. In addition, all power converters are operated under the continuous conduction mode $(\mathrm{CCM})$ and the harmonics are also ignored.

\begin{tabular}{|l|c|}
\hline \multicolumn{2}{|c|}{ Table : 1 PV module Parameters } \\
\hline Maximum Power & 213.5 Watts \\
\hline Number of parallel strings & 40 \\
\hline Number series modules & 10 \\
\hline Open circuit voltage & 36.3 Volts \\
\hline Shot circuit current & 7.84 Ampere \\
\hline
\end{tabular}

2) wind energy system modeling:

Model of wind turbine with PMSG Wind turbines cannot fully capture wind energy. Output aerodynamic power of the wind-turbine is expressed as:

$$
P_{\text {Turbine }}=\frac{1}{2} \rho A C_{p}(\lambda, \beta) v^{3}
$$

where, $\rho$ is the air density (typically $1.225 \mathrm{~kg} / \mathrm{m} 3$ ), $A$ is the area swept by the rotor blades (in $\mathrm{m} 2$ ), $C P$ is the coefficient of power conversion and $v$ is the wind speed (in $\mathrm{m} / \mathrm{s}$ ).

The tip-speed ratio is defined as:

$$
\lambda=\frac{\omega_{m} R}{v}
$$

where $\omega_{m}$ and $R$ are the rotor angular velocity (in $\mathrm{rad} / \mathrm{sec}$ ) and rotor radium (in $\mathrm{m}$ ), respectively.

The wind turbine mechanical torque output $m T$ given as:

$$
T_{m}=\frac{1}{2} \rho A C_{p}(\lambda, \beta) v^{3} \frac{1}{\omega_{m}}
$$

The power coefficient is a nonlinear function of the tipspeed ratio $\lambda$ and the blade pitch angle $\beta$ (in degrees). Then Power output is given by

$$
P_{\text {Turbine }}=\frac{1}{2} \rho A C_{p_{\max }} v^{3}
$$

A generic equation is used to model the power coefficient $C_{P}$ based on the modeling 2 turbine characteristics described in [2], [7-9] and [11] as:

$$
C_{p}=\frac{1}{2}\left(\frac{116}{\lambda_{i}}-0.4 \beta-5\right) e^{-\left(\frac{21}{\lambda_{i}}\right)}
$$

For each wind speed, there exists a specific point in the wind generator power characteristic, MPPT, where the output power is maximized. Thus, the control of the 
WECS load results in a variable-speed operation of the turbine rotor, so the maximum power is extracted continuously from the wind.

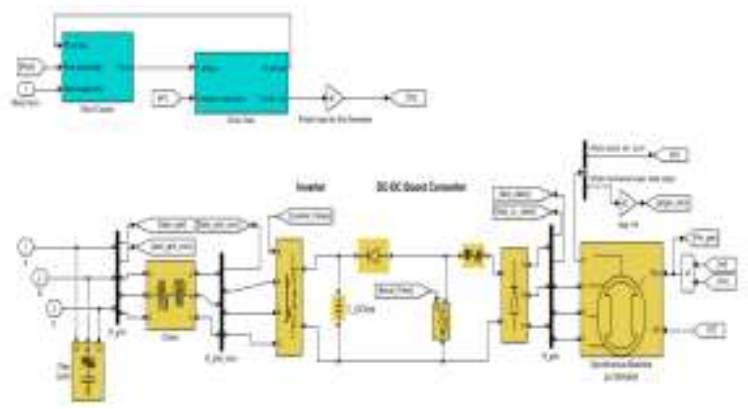

Figure 6 modeled Wind system

This mechanism uses the variable torque output $\mathrm{w}_{\mathrm{m}}$ and tries to optimize the output current and voltage waveform to its maximum value.

\section{3) Modeling of Compensator with RLS algorithm}

Recursive least squares (RLS) is an adaptive_algorithm that recursively finds the coefficients that minimize a weighted linear least squares cost function relating to the input signals.

Because of its simplicity and improved performance, RLS algorithms are widely used in many applications. Generation of Compensating Current using RLS Algorithm is used in compensator so as to get DC link active current parameter $\left(\mathrm{A}_{\mathrm{dcx}}\right)$, maintaining $\mathrm{DC}$ link voltage with the constant value of each phase and to make ripple free in the waveform.

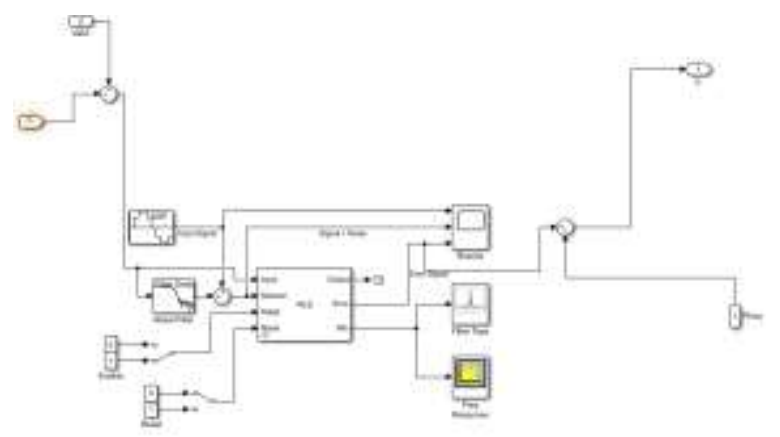

Figure 7 Modeled RLS algorithm for compensator

The value of instantaneous active current can be achieved by the compensator so as to balance the power loss and active power difference between load and supply system. Fig.7 shows the functioning of RLS algorithm where $V_{\text {ref }}$ reference DC link voltage and $\mathrm{V}_{\mathrm{dc}}(\mathrm{i})$ DC link voltage having instantaneous sampling value.

In source voltage, harmonics are not present, so instantaneous voltage given as

$$
V_{x}(t)=V_{a x}(t)
$$

www.ijoscience.com
For each phase, the reference active current is given as

$$
i_{a x}(t)=A_{x} V_{x}(t)
$$

The instantaneous reference compensating current specified as

$$
i(t)=i_{x}(t)-i_{a x}(t)
$$

The RLS algorithms are known for their excellent performance when working in time varying environments but at the cost of an increased computational complexity and some stability problems. In this algorithm the filter tap weight vector is updated using Eq

$$
\begin{aligned}
& w(n)=\bar{w}^{T}(n-1)+k(n) \overline{e_{n-1}}(n) \\
& k(n)=u(n) /\left(\lambda+X^{\prime}(n) u(n)\right) \\
& u(n)=\bar{w}_{\lambda}^{-1}(n-1) X(n)
\end{aligned}
$$

Eq. (2) and (3) are intermediate gain vector used to compute tap weights. Where $\lambda$ is a small positive constant very close to, but smaller than 1 .

The above algorithm is made to generate pulses for the compensating device. The pulses is generated by reading the ouput voltage from the transformer and genertaing a difference from the reference signal. The error calculated is taken as input for the RLS algorithm. The method traces the least quare error and generates a optimum ouput. The least square is compared with the power losses in the transmission and a pulse is generated accordingly taking in account the current reference. Thus the pulse hgenerated is made to feed the bridge circuit of the compensator which are made by using IGBT switches.

The compensator designed consis of two neutral clamped capacitors with six MOSFETS which are made to generate power in such a manner that per phase is controlled by two MOSFETS. These are switching devices that attain their pulses from the RLS based algorith that compare both the voltage and current outputs from the line. Any difference calculated is converter into pulses via pulse width modutaion genetaror.

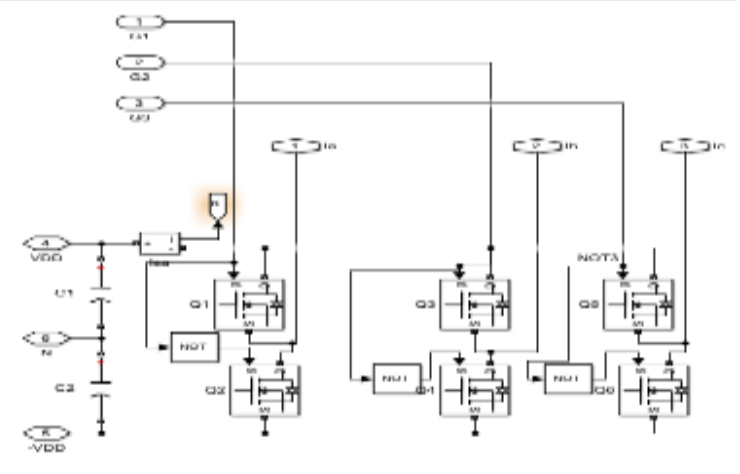


Figure 8 Modeled Compensator driven by RLS algorithm

\section{RESULTS}

The analysis of the model has been done in MATLAB/SIMULINK environment. MATLAB combines a desktop environment tuned for iterative analysis and design processes with a programming language that expresses matrix and array mathematics directly. It allows graphical programming to design your system in a simulation environment.

The discrete mode sampling time is kept to be $\mathrm{Ts}=5 \mathrm{x} 10^{-}$ ${ }^{6}$. The AC output voltages is then sent to the load. The model can further be integrated with the grid system. In order to overcome the poor and unacceptable performance of the conventional solutions during unsymmetrical loads, an innovative control strategy is anticipated.

- The present work discusses the control strategies of a hybrid system using two compensators STATCOM and modified compensator controlled with RLS algorithm respectively.

- The gate signals provided to the IGBTs drawn after treating the error signals through a RLS algorithm.

- The model is made fit to drive a residential load with minimum distortion in the voltage waveform as well as integration with grid

- The system is being simulated for 1 second for simulation purpose in MATLAB/SIMULINK environment

The Result analysis of the modern has been arranged in this chapter in the following manner

1. Outputs from the hybrid system

2. Case 1: Hybrid system modeled with STATCOM compensator

3. Case2: Hybrid system modeled with proposed compensator controlled by RLS algorithm.

4. Load analysis

The work done focuses on solar PV hybrid system whose DC power output is being fed to the inverter and converted into 3 phase AC output. Compensator is used before feeding it to the grid network and driving the residential load. The work establishes a comparative analysis of the work between STATCOM and the proposed compensator with RLS algorithm. The field of focus of our work is on improving the THD as well as power output of the system thereby serving the purpose of both enhanced and smooth power output values.

1: Outputs from the hybrid system

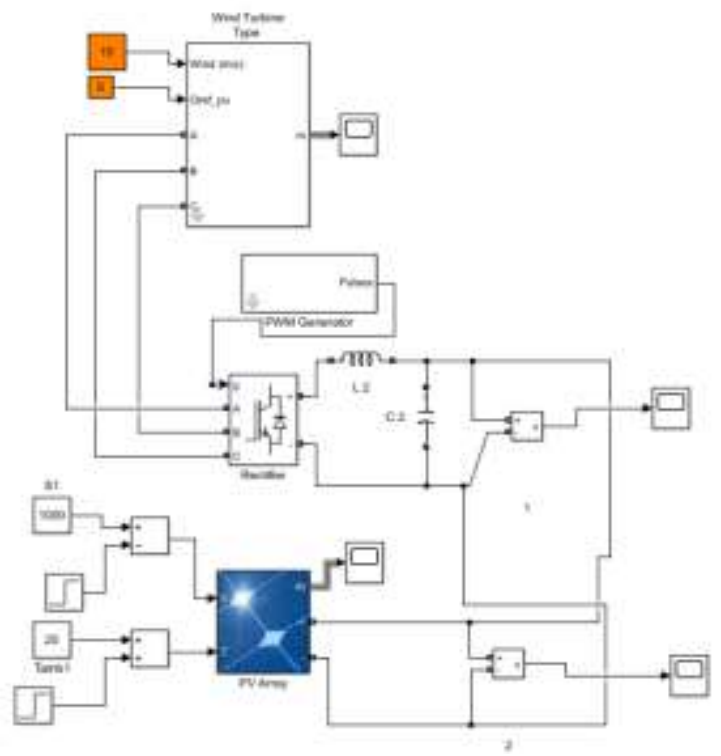

Figure 9: MATLAB/SIMULINK model of hybrid system

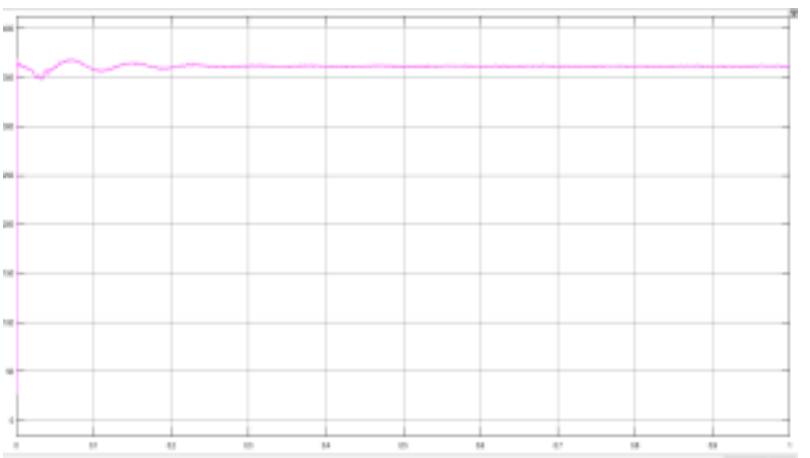

Figure 10: DC voltage output from the hybrid system The figure 5.2 shows that the DC power output from the system is found to be approximately 360volys. This voltage is then fed to the inverter for the conversion from Dc to three phase AC output.

2: Case 1: Hybrid system modeled with STATCOM compensator

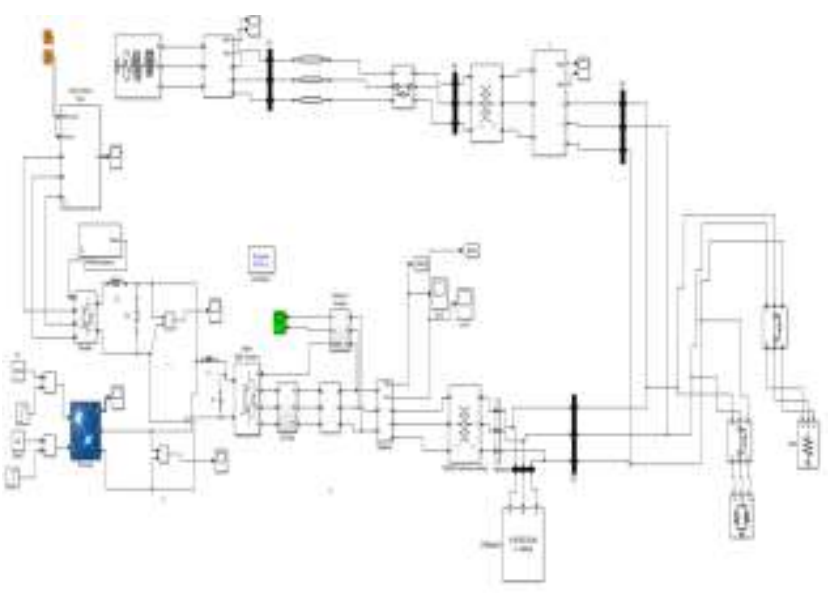


Figure 11 Hybrid system modeled with STATCOM

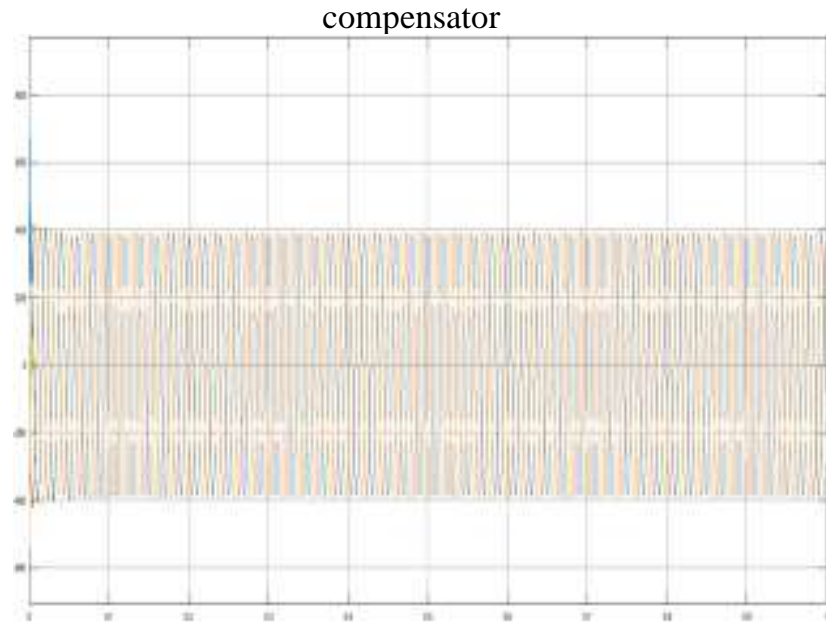

Figure 12 Voltage output of hybrid system with STATCOM

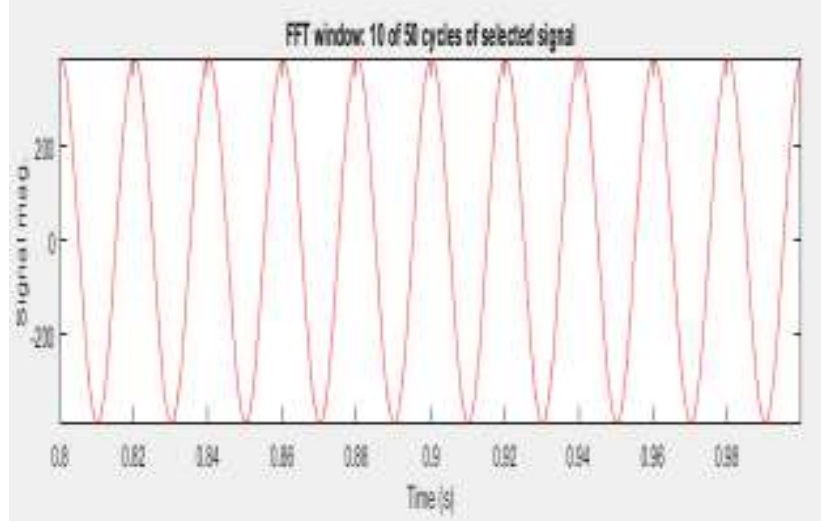

Figure 13 FFT analysis of voltage output of hybrid system with STATCOM

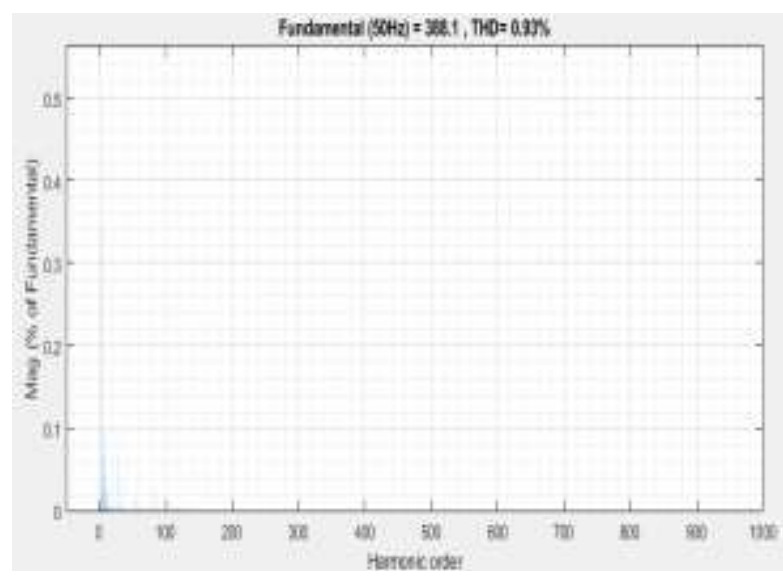

Figure $14 \mathrm{THD}=0.93 \%$ in voltage output of hybrid system with STATCOM

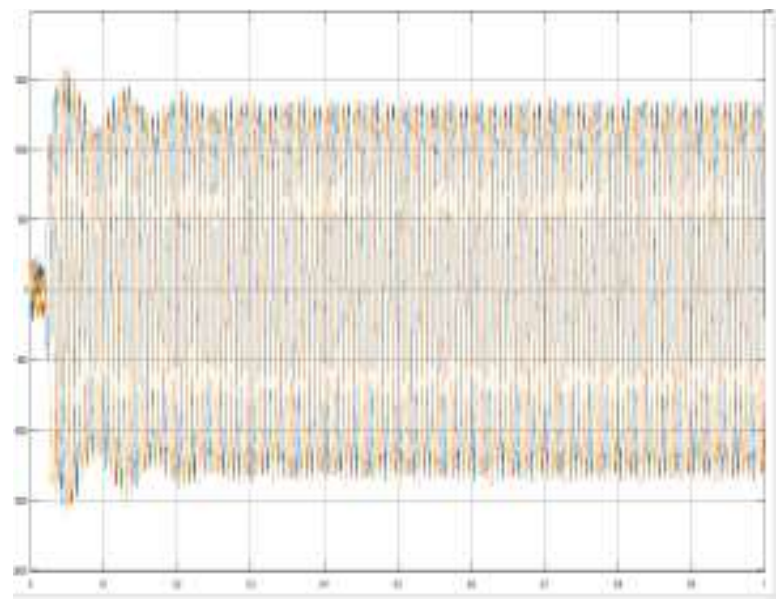

Figure 15 Output current from hybrid system with STATCOM

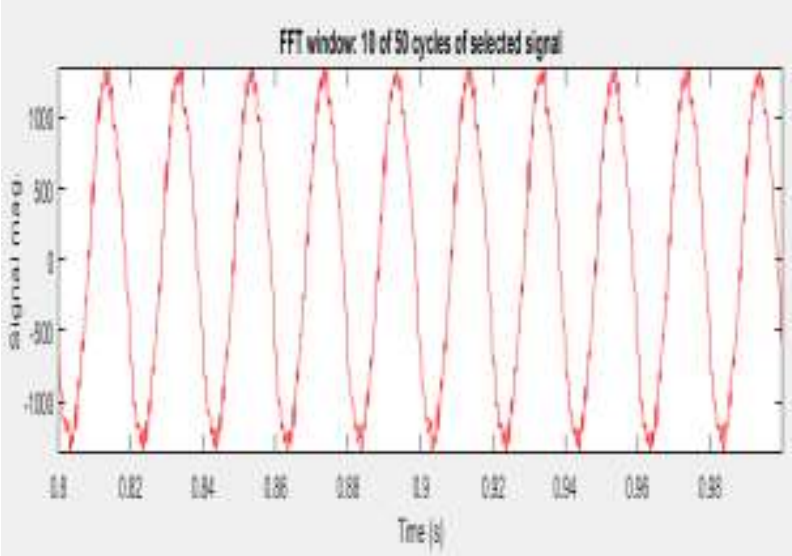

Figure 16 FFT analysis of Output current from hybrid system with STATCOM

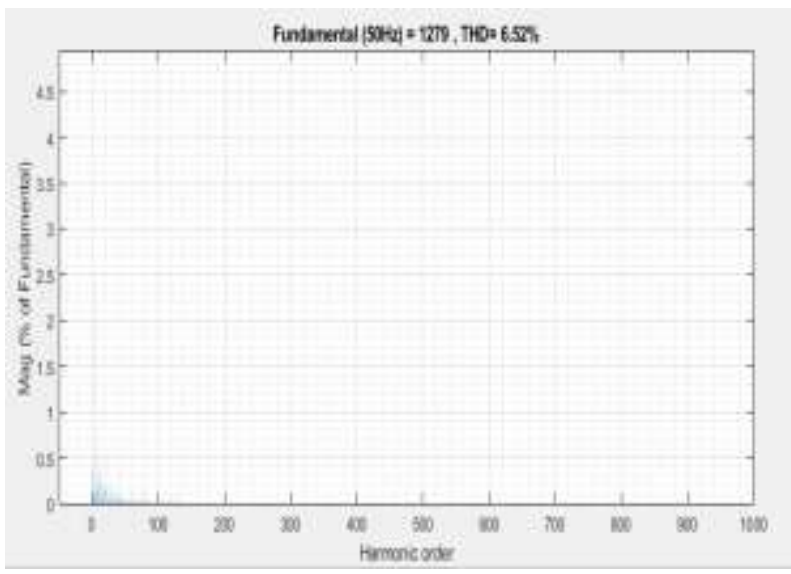

Figure $17 \mathrm{THD}=6.52 \%$ in Output current from hybrid system with STATCOM 


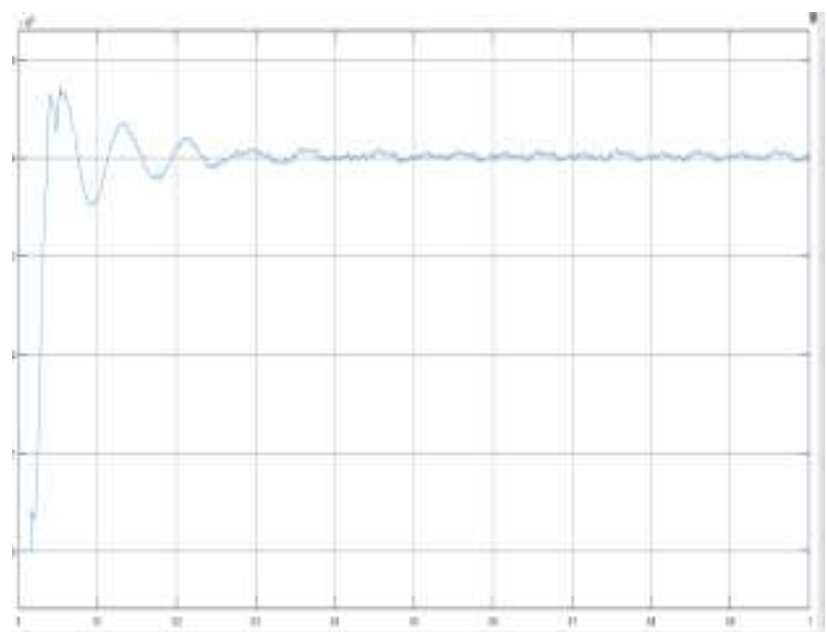

Figure 18 Active Power output from hybrid system with STATCOM

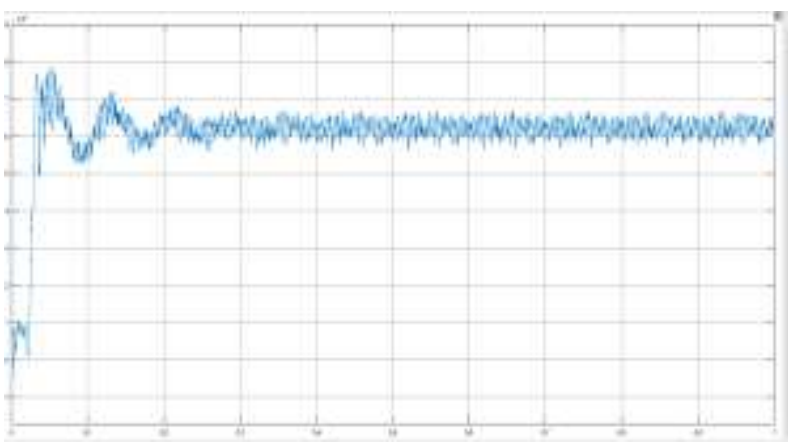

Figure 19 Reactive output from hybrid system with STATCOM

3 Case2: Hybrid system modeled with proposed compensator controlled by RLS algorithm

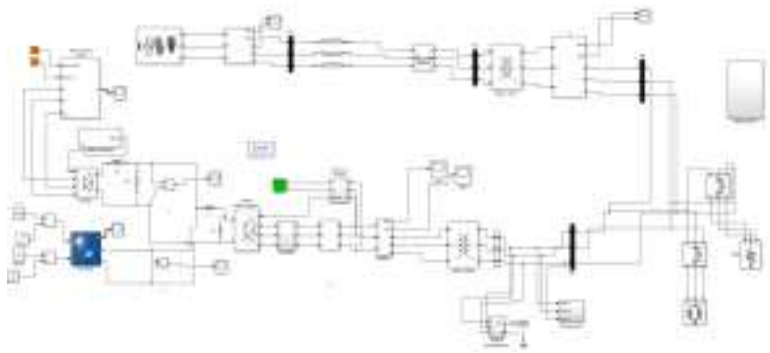

Figure 20 Hybrid system modeled with proposed compensator controlled by RLS algorithm

The fig shows the hybrid solar PV system being replaced with compensator having RLS algorithm in place of STATCOM. The analysis of distortion level is being measure in both voltage and current output waveforms. Further the output power available to drive the residential type of loads is also studied. The phase to phase voltage ouput is 400 Volts.

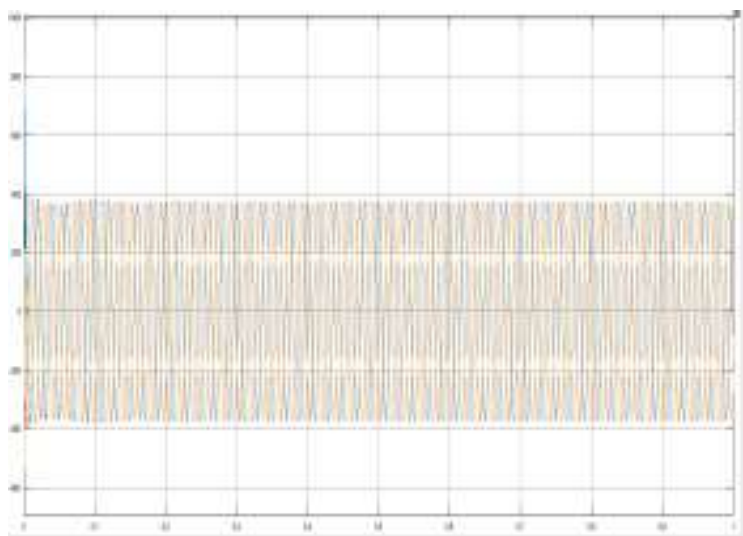

Figure 21 Output voltage from the compensator with RLS algorithm

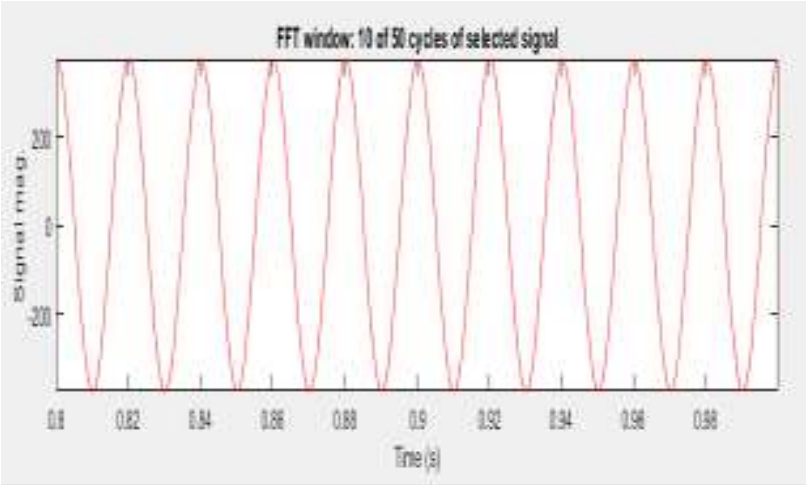

Figure 22 FFT analysis of Output voltage from the compensator with RLS algorithm

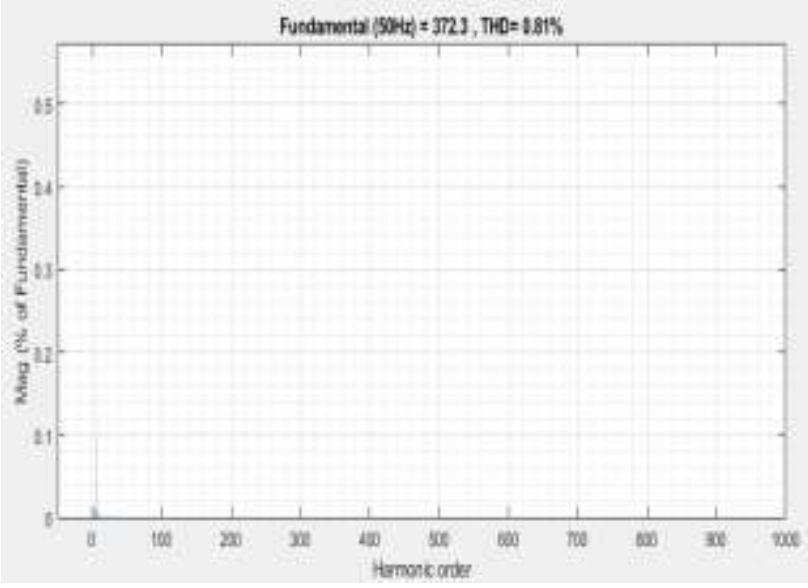

Figure $23 \mathrm{THD}=0.81 \%$ in Output voltage from the compensator with RLS algorithm 


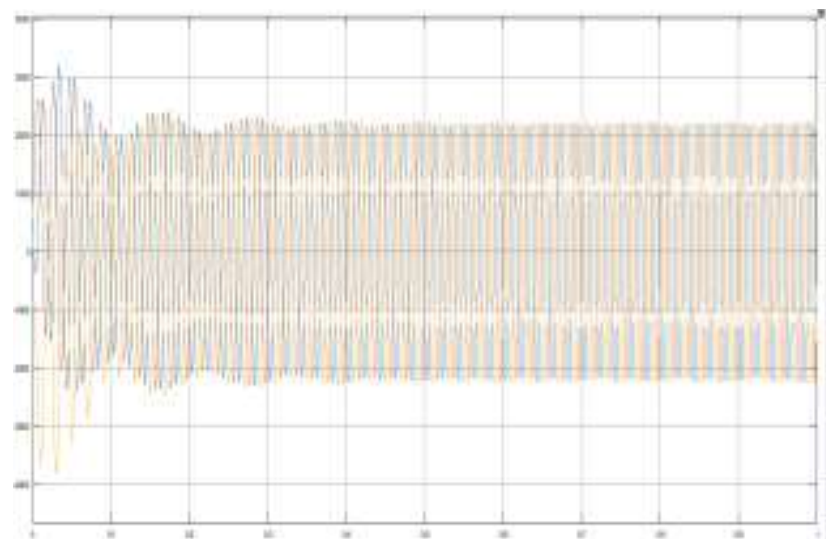

Figure 24 Output current from the compensator with RLS algorithm

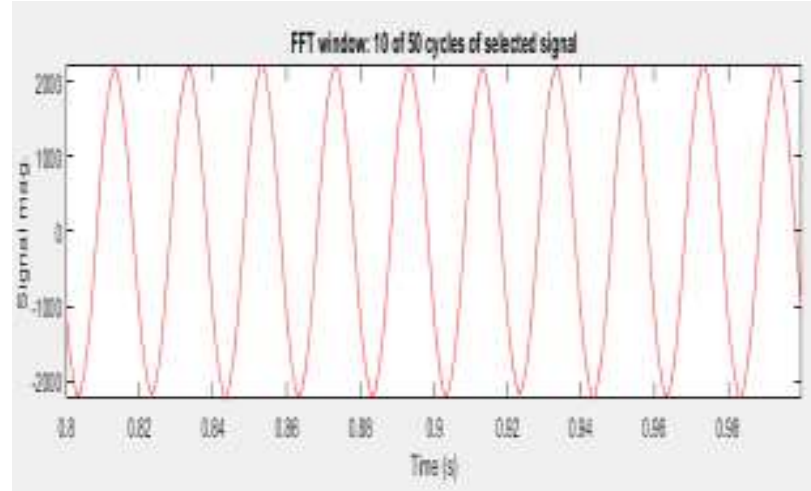

Figure 25 FFT analysis of Output current from the compensator with RLS algorithm

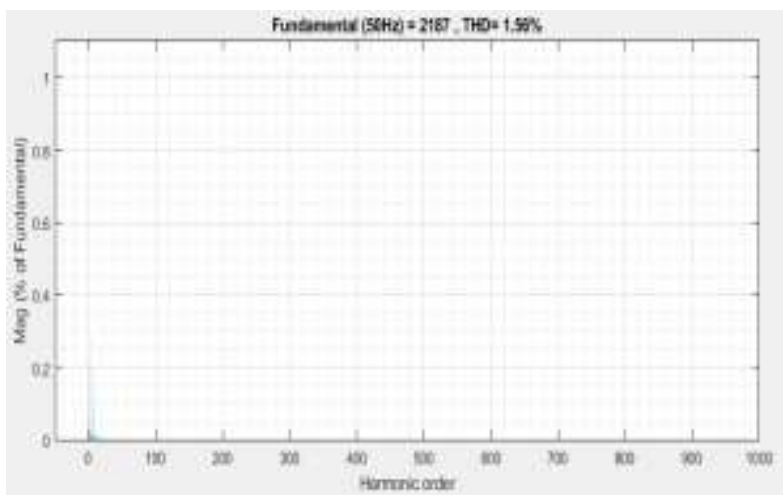

Figure $26 \mathrm{THD}=1.56 \%$ in Output current from the compensator with RLS algorithm

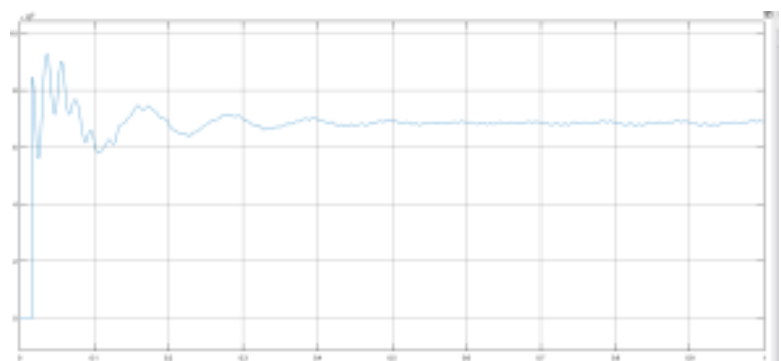

Figure 27 Active Power Output from the compensator with RLS algorithm

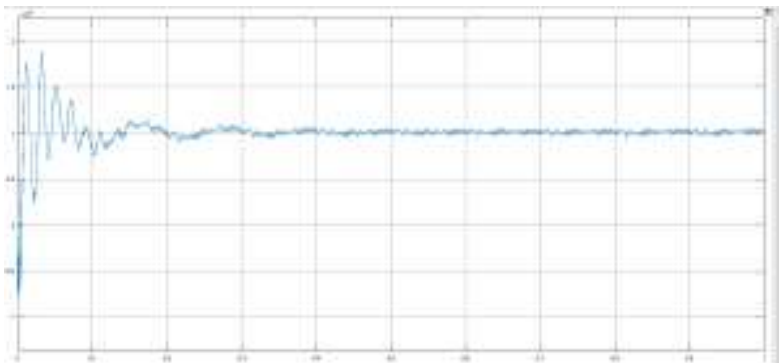

Figure 28 Reactive Power Output from the compensator with RLS algorithm

4. Load Driving Capacity

For making the system efficient for driving residential type of loads the voltage output is is kept to be approximately 400 volts phase to phase. There are two type of loads considered for analysis that is pure resistive and the second one Inductive and resistive. On doing the analysis it was clear that available power in case of rls algorithm compensator is more as compared to basic statcom device. Also the level of distortion in the voltage and current output waveforms was considerable reduced hence making the load driven by a left distorted and more power output wave form.

The above waveform of the voltage output shows that the magnitude at the load terminal is kept constant to 400 volts in case of phase to phase voltage. This is because the phase to phase residential load voltage is kept same in India. Also the analysis is done for three phase voltage such that its maximum driving capacity is being analyzed. The analysis concludes the enhancement in active power output available at the load terminal to be enhanced with the proposed compensator having RLS algorithm as compare to STATCOM and hence making the system viable for driving the loads of more power rating

\section{VALIDATION}

This chapter discusses the total harmonic distortion values in the voltage output and current output waveform of the system. We discuss the comparative analysis of THD $\%$ in the system having basic compensator with the proposed compensator controlled with recursive least square algorithm the active power outputs are 
being compared to depict the enhancement in results .

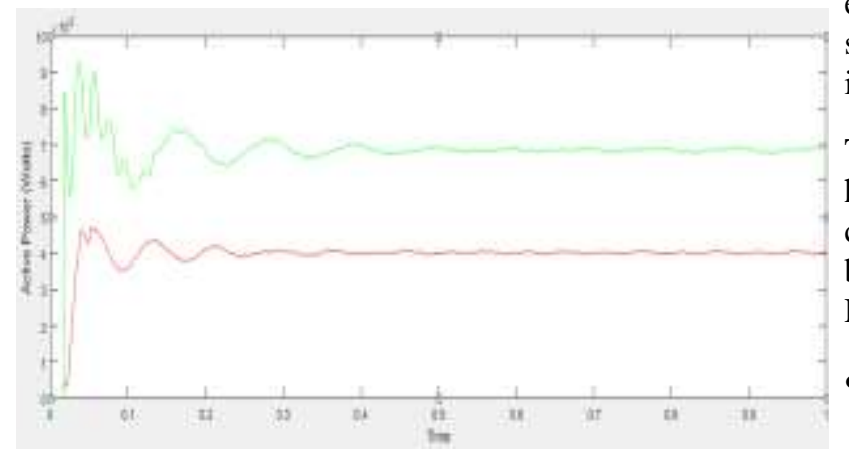

Figure 29 Comparison of active power outputs from the system having STATCOM with compensator designed with RLS algorithm

Comparative analysis of active power output from the hybrid system having stucco module with the hybrid system having compensator controlled with RLS algorithm. It shows that active power output from the system having STATCOM is approximately $400 \mathrm{KW}$ and that from the system having proposed compensator has a power output of approximately $690 \mathrm{KW}$. Hence it has considerable enhancement in the output power from the system. This system is then made to drive residential loads. Further the system is also integrated with grid system to enhance its efficiency and reliability.

\begin{tabular}{|c|c|c|}
\hline \multicolumn{2}{|c|}{ Table 2: Comparison of THD levels in current and voltage } \\
output from the two systems \\
\hline Device used & $\begin{array}{c}\text { THD in input voltage } \\
\text { output }\end{array}$ & $\begin{array}{c}\text { THD in } \\
\text { current output }\end{array}$ \\
\hline $\begin{array}{c}\text { With } \\
\text { STATCOM }\end{array}$ & $0.93 \%$ & $6.52 \%$ \\
\hline $\begin{array}{c}\text { With } \\
\text { compensator } \\
\text { with RLS } \\
\text { algorithm }\end{array}$ & $0.81 \%$ & $1.56 \%$ \\
\hline
\end{tabular}

Further the FFT analysis of the current output waveform and voltage output waveform is done in both the systems having STATCOM and compensator with RLS algorithm and the total harmonic distortion THD \% is being made. The table 2 shows the reduction in THD \% of the voltage and current output of the system having compensator with proposed RLS algorithm.

\section{VII.CONCLUSION}

At present, large-scale wind/solar hybrid system is of great potential for development. The large scale wind/solar hybrid system is of higher reliability compared with wind power generation alone and solar power generation alone.

www.ijoscience.com
Loads of a DC micro grid form active loads can be interfaced to the power distribution grid via power electronics converters. Proper utilization of the energy stored in the compensators can help shape the transient imposed on the power distribution grid by volatile loads.

The simulation result shows that large-scale wind/solar hybrid system with the control strategy proposed for the compensator is better to transients in the voltage. They are being combined with the grid for further enhancement. Following main conclusions were drawn:

- The total harmonic distortion in the voltage output waveform which will be made to drive load using only STATCOM is found to be $0.93 \%$ and the total harmonic distortion in the voltage waveform output using proposed compensator with RLS algorithm is found to be $0.81 \%$.

- The total harmonic distortion in the current output waveform which will be made to drive load using only STATCOM is found to be $6.52 \%$ and the total harmonic distortion in the current waveform output using proposed compensator with RLS algorithm is found to be $1.56 \%$.

- The comparison of output waveform for the active power available at the load terminal is found to be approximately $400 \mathrm{KW}$ with the STATCOM and 700 $\mathrm{KW}$ with the proposed compensator having RLS algorithm it was improved to $700 \mathrm{KW}$. Also the system is integrated with grid

- The system is made efficient for driving residential loads having phase to phase voltage 400 volts.

The above description concludes that the hybrid system is made efficient for driving the residential loads having enhanced active power output at its terminal. The voltage available has been made less distorted and the THD level in current output has also came down. The proposed compensator with RLS algorithm has been found to be better in terms of reducing the TDH levels in the voltage as well as current waveform and improvement in active power available at the load terminal

\section{FUTURE SCOPE}

The modulation technique is easy and simple to be implemented; use of proper facts devices can make it more robust and easy to handle inverter.

With the advent of more powerful artificial intelligence, the requirements for low computational complexity and memory consumption of the algorithms will drop and it might be even possible to implement more complicated and more efficient algorithms. Therefore, it is certainly true that the area of compensator is and for a long time will remain widely opened sphere for scientific research and commercial applications 


\section{REFERENCE}

[1] Ying Liu ; Wenping Qin "Modelling of large-scale wind/solar hybrid system and influence analysis on power system transient voltage stability" DOI: 10.1109/ICIEA.2017.8282892 18-20 June 2017

[2] Hamdy M. Sultan, Ahmed A. Zaki Diab "Evaluation of the Impact of High Penetration Levels of PV Power Plants on the Capacity, Frequency and Voltage Stability of Egypt's Unified Grid" Published: 11 February 2019

[3] A Arabali, M Ghofrani, M Etezadi-Amoli et al., "Stochastic performance assessment and sizing for a hybrid power system of Solar/Wind/Energy storage[J]", IEEE Transactions on Sustainable Energy, vol. 5, no. 2, pp. 363-371, 2014.

[4] S. Wang, G. Tian "Coordination control of wind/PV hybrid system" Taiyangneng Xuebao/Acta Energiae Solaris Sinica 31(5):654-660 May 2010

[5] Y. A. Kazachkov, J.W. Feltes, and R. Zavadil,,” Modeling Wind Farms For Power System Stability Studies", IEEE Power Engineering Society General Meeting, 2003,Vol.3,PP 15261533.

[6] Pablo Ledesma," Doubly Fed Induction Generator Model for Transient Stability Analysis", IEEE Transactions on Energy Conversion, Vol. 20, No. 2, June 2005, PP 388-397.

[7] Istvan Erlich, Jorg Kretschmann, Jens Fortmann, Stephan Mueller-Engelhardt and Holger Wrede," Modeling Of Wind Turbines Based On Doubly-Fed Induction Generators For Power System Stability Studies", IEEE Transactions On Power Systems, Vol. 22, No. 3, August 2007, PP 909-919.

[8] Yazhou Lei, Alan Mullane, Gordon Lightbody and Robert Yacamini," Modeling of The Wind Turbine With A Doubly Fed Induction Generator For Grid Integration Studies", IEEE Transactions On Energy Conversion, Vol. 21, No. 1, March 2006, PP 257-264.

[9] Andres Feijoo, Jose Cidras, Camilo Carrillo," A Third Order Model for The Doubly-Fed Induction Machine", Electric Power Systems Research, Vol.56, 2000, PP 121-127.

[10] J.Kretschmann, H.Wrede, S. Mueller-Engelhardt, I. Erlich, "Enhanced Reduced Order Model Of Wind Turbines With DFIG For Power System Stability Studies", First International Power And Energy Coference, November 28-29, 2006, Putrajaya, Malaysia 